\title{
DISERTACIONES
}

Estudios sobre imágenes en el nuevo ecosistema mediático

ISSN: $1856-9536$

Doi: https://doi.org/10.12804/revistas.urosario.edu.co/disertaciones/a.8298

Volumen 13, Número 2 / Julio-diciembre 2020

Versión PDF para imprimir desde

http://revistas.urosario.edu.co/index.php/disertaciones

Para citar este artigo: Ushinohama, T., \& Roxo, M. (2020). A distribuição da transmissão audiovisual da

\section{A DISTRIBUIÇÃO DA TRANSMISSÃO AUDIOVISUAL DA COPA DO MUNDO DE 2018 NA PERSPECTIVA BRASILEIRA}

La distribución de la transmisión audiovisual de la Copa del Mundo de 2018 en la perspectiva brasilera

The Distribution of Audiovisual Transmission of the 2018 World Cup from the Brazilian Perspective

Tatiana Ushinohama, Universidade Federal Fluminense - UFF-RJ (Brasil)

tatianazuardi@globo.com

Marco Roxo, Universidade Federal Fluminense - UFF-RJ (Brasil)

marcos-roxo@uol.com.br

Recebido: 29 de setembro de 2019

Aprovado: 08 de março de 2020

Data de pré-publicação: 7 de julho de 2020

\section{RESUMO}

A Copa do Mundo interrompe totalmente cotidianidade da sociedade brasileira, domina a razão e aflora fortes emoções de modo que assistir a um jogo da seleção nacional é um ato de comunicação mediada imprescindível. O objetivo deste artigo é descrever e analisar a distribuição de conteúdos oriundos da transmissão de uma partida de futebol da Copa do Mundo de 2018 realizada pelas emissoras de televisão brasileiras detentoras da 


\section{DISERTACIONES}

\section{ESTUDIOS}

Estudios sobre imágenes en el nuevo ecosistema mediático

ISSN: $1856-9536$

Doi: https://doi.org/10.12804/revistas.urosario.edu.co/disertaciones/a.8298

Volumen 13, Número 2 / Julio-diciembre 2020

Versión PDF para imprimir desde

http://revistas.urosario.edu.co/index.php/disertaciones

licença dos direitos de transmissão do evento, seja na grade de programação dos canais televisivos ou na internet em aplicativos ou sites. Para isso, utiliza-se o método do estudo de caso múltiplos delimitado por Yin. Como resultado tem-se que as três emissoras brasileiras licenciadas distribuíram a transmissão por 14 configurações diferentes entre emissões televisivas e internet. Argumenta-se que a ideia de cadeia produtiva proposta pela instituição responsável pelo evento (FIFA) visa unificar mundialmente a transmissão televisiva esportiva, mas, na prática, sofre interferência de elementos nacionais na distribuição. Por isso, tão importante quanto produzir a transmissão do evento, é distribuí-la pelo mundo, ato que compete às emissoras nacionais licenciadas pela FIFA, pois elas adaptam as transmissões às variações regionais e locais nas questões políticas, técnicas e sociais.

Palavras-chave: distribuição, transmissão audiovisual, copa do mundo, esporte, televisão.

\section{RESUMEN}

La Copa del Mundo interrumpe totalmente la cotidianidad de la sociedad brasilera, domina la razón y aflora fuertes emociones de modo que ver un juego de la selección nacional es un acto de comunicación mediada imprescindible. El objetivo de este artículo es describir y analizar la distribución de contenidos oriundos de la transmisión de una partida de fútbol de la Copa del Mundo de 2018 realizada por las cadenas de televisión brasileras poseedoras de la licencia de los derechos de transmisión del evento, ya sea en la franja de programación de los canales televisivos o en internet en aplicaciones o páginas web. Para esto, se utiliza el método de estudio de caso múltiple delimitado por Yin. Como resultado se obtiene que las tres cadenas de televisión brasileras licenciadas distribuyeron la transmisión por 14 configuraciones diferentes entre emisiones televisivas e internet. Se argumenta que la idea de cadena productiva propuesta por la institución responsable del evento (FIFA) busca unificar mundialmente la transmisión televisiva deportiva, pero en la práctica, sufre interferencia de elementos nacionales en la distribución. Por esto, tan importante como producir la transmisión del evento es distribuirla por el mundo, acto que compete a las cadenas nacionales licenciadas por la FIFA, pues ellas adaptan las transmisiones a las variaciones regionales y locales en las cuestiones políticas, técnicas y sociales.

Palabras clave: distribución, transmisión audiovisual, Copa del Mundo, deporte, televisión.

\section{ABSTRACT}

The FIFA World Cup completely interrupts the Brazilian society's daily life, as this reason dominates and emerges strong emotions, thus making watching the game with the national team an essential act of media communication. This study thus describes and analyzes the distribution of content originating from the transmission of a soccer game from the 2018 FIFA World Cup offered by Brazilian television networks that hold the license for the event's broadcasting rights, either in the programing strip of television channels or on the Internet through web applications. To do so, Yin's delimited multiple case study method was employed. The study results revealed that the three licensed Brazilian 


\section{DISERTACIONES}

\section{ESTUDIOS}

Estudios sobre imágenes en el nuevo ecosistema mediático

ISSN: $1856-9536$

Doi: https://doi.org/10.12804/revistas.urosario.edu.co/disertaciones/a.8298

Volumen 13, Número 2 / Julio-diciembre 2020

Versión PDF para imprimir desde

http://revistas.urosario.edu.co/index.php/disertaciones

television networks distributed the transmission through 14 different configurations between television broadcasts and the Internet. Further, we argue that while the idea of productive chain proposed by the institution responsible for the event (FIFA) seeks to unify sports television broadcasting worldwide, in practice, it suffers interference from national aspects in distribution. For this reason, it is vital to produce the event broadcast to distribute it worldwide. This is the responsibility of the national channels licensed by FIFA, as they adapt the broadcasts to regional and local variations in political, technical, and social issues.

Keywords: Distribution, broadcasting, world cup, sport, television.

De quatro em quatro anos, em um ritual contemporâneo, a sociedade brasileira suspende seus afazeres cotidianos e acompanha a transmissão direta e "ao vivo" dos jogos da sua seleção na Copa do Mundo de Futebol masculino. Esse ato de assistir a seleção para o torcedor traduz-se em "[...] um novo espaço mítico com as suas aberturas, seus horizontes indefinidos, seus heróis. Um universo dado quase como uma contra-sociedade, modelo purificado da nossa, que cultiva igualdade, o mérito e a lealdade" (Vigarello \& Holt, 2009 p. 475). Fato que faz as emissoras de televisão brasileiras (aberta e paga) disputarem intensamente os direitos de transmissão do evento junto à FIFA, anos antes de o campeonato acontecer, pois a detentora dos direitos imagéticos tem a possibilidade de distribuir o conteúdo audiovisual da competição em vários espaços mediáticos, como os da televisão e da internet.

Por isso, o objetivo desta pesquisa é descrever e analisar a distribuição do conteúdo oriundo da transmissão de uma partida de futebol da Copa do Mundo de 2018 realizada pelas emissoras de televisão brasileiras, detentoras da licença dos direitos de transmissão do evento, seja na grade de programação dos canais televisivos ou na internet, em aplicativos ou sites, a fim de apurar como as empresas, transnacional (FIFA) e nacionais (emissoras de televisão), trabalham uma com a outra na difusão da cultura esportiva.

Para isso, utilizou-se, como método de investigação, o estudo de casos múltiplos delimitado por Yin (2001), uma vez que se trata de uma situação única, com inúmeras variáveis fora do domínio do pesquisador que se inter-relacionam de forma complexa. Essa estratégia de pesquisa empírica possibilita investigar "[...] um fenômeno contemporâneo dentro de seu contexto da vida real, especialmente quando os limites entre o fenômeno e o contexto não estão claramente definidos" (Yin, 2001, p. 32).

Assim, na primeira parte, o artigo apresenta a estrutura atual para a aquisição da licença dos diretos de transmissão audiovisual da Copa do Mundo de Futebol de 2018 pelas emissoras brasileiras; na segunda parte define-se o objeto de pesquisa e descreve-se o método de investigação aplicado. Na terceira parte, o artigo expõe os dados, para, na quarta parte, confrontá-los com as perspectivas teóricas dos estudos televisivos mundiais. 0 artigo termina com uma análise ensaística sobre a hipótese de que as instituições nacionais modelam a prática de visualização do 


\section{DISERTACIONES}

ESTUDIOS

Estudios sobre imágenes en el nuevo ecosistema mediático

ISSN: $1856-9536$

Doi: https://doi.org/10.12804/revistas.urosario.edu.co/disertaciones/a.8298

Volumen 13, Número 2 / Julio-diciembre 2020

Versión PDF para imprimir desde

http://revistas.urosario.edu.co/index.php/disertaciones

evento por meio das estruturas comunicacionais físicas (sistema televisivo, tv, aplicativos e sites) como uma tentativa de responder a um aparente desejo do seu espectador-projetado, apesar de receberem um produto cultural concluído e global elaborado por uma entidade transnacional, a FiFA, que comanda a produção e distribuição das transmissões esportivas de futebol.

\section{Os direitos de transmissão da copa do mundo}

A Copa do Mundo de Futebol masculino é um evento esportivo mundial que reúne 32 seleções $^{1} \mathrm{em}$, geralmente, um país sede para uma competição a cada quatro anos, organizado por uma entidade esportiva internacional, a FIFA. Inicialmente, a FIFA era somente a administradora e organizadora das competições mundiais, de maneira que licenciava as emissoras de radiodifusão mundiais que distribuíram o evento, deixando a elaboração da transmissão sob a responsabilidade de conglomerados comunicacionais formados por empresas locais, nos países-sede da competição.

O evento começa a ser transmitido, audiovisualmente, em 1954, ${ }^{2}$ de forma direta e "ao vivo"3 (Fechine, 2008), ou seja, a recepção audiovisual acontece quase que simultaneamente à realização das ações dos jogadores nas partidas, por intermédio de um meio de comunicação de massa, a televisão.

Em 2007, a FIFA assume o gerenciamento comunicacional da Copa do Mundo e cria uma subdivisão da entidade, a TV FIFA, com o objetivo de "[...] oferecer a melhor experiência possível de exibição de futebol para as telas". Essa decisão centralizou sob a sua alçada a venda, a distribuição e a produção dos serviços de radiodifusão envolvendo o campeonato. $O$ departamento surgiu no momento em que novas possibilidades e demandas emergiam no cenário mediático em função da troca da tecnologia analógica pela digital, que projetava a perspectiva de uma convergência das mídias e, consequentemente, a multiplicação dos conteúdos pelos meios de comunicação, o que dificultaria o controle da entidade sobre o conteúdo audiovisual do evento.

Assim, a fifa preservou o seu domínio sobre a sua principal fonte de receita nos ciclos de eventos, a venda dos diretos de transmissão televisiva, com um pretexto de ofertar um material mediático de qualidade para as emissoras mundiais por ela licenciadas.

1 A partir da Copa do Mundo de 2026, o Campeonato terá 48 seleções participando do evento. Disponível em:<https://www.fifa.com/about-fifa/news/y=2017/m=1/news=fifa-council-unanimously-decides-on-expansion-of-the-fifa-world-cuptm--2863100.html>. Acesso em: 09 ago. 2018.

2 Primeira Copa do Mundo a ser transmitida audiovisualmente por radiodifusão foi a de 1954, na Suíça. Disponível em: <https://www.fifa.com/about-fifa/news/y=1997/m=10/news=football-and-television-natural-partnership-72042.html>. Acesso em: 20 jan.2019.

3 Segundo Fechine (2008), há uma distinção entre os significados de transmissão direta e a transmissão "ao vivo". Transmissão direta refere-se ao processo técnico que constrói um conteúdo em que a edição é feita sob a supervisão do público de forma a incorporar os imprevistos durante a gravação. Transmissão "ao vivo" refere-se à transposição espaço temporal que o meio faz levar o conteúdo até o receptor. Ambos os significados estão presentes em uma transmissão audiovisual esportiva.

4 Tradução livre de: "delivering the best-possible football viewing experience to screens". Disponível em: < https://www.fifa.com/about-fifa/tv/who-we-are.html>. Acesso em: 09 ago. 2018. 


\section{DISERTACIONES}

ESTUDIOS

Estudios sobre imágenes en el nuevo ecosistema mediático

ISSN: $1856-9536$

Doi: https://doi.org/10.12804/revistas.urosario.edu.co/disertaciones/a.8298

Volumen 13, Número 2 / Julio-diciembre 2020

Versión PDF para imprimir desde

http://revistas.urosario.edu.co/index.php/disertaciones

Com isso, desde 2007, a receita da FIFA com a venda dos diretos de transmissões televisivas das Copas vem aumentando em valor bruto, conforme o gráfico 1. Esse fato ocorre em função da assinatura de novos contratos de direitos de mídia com vários territórios, pois a abrangência da entidade, atualmente, encontra-se em 211 países ou territórios filiados. ${ }^{5}$

Tabela 1. Descrição da Receita da fIFA por ciclo

\begin{tabular}{|c|c|c|c|c|c|c|}
\hline & \multicolumn{6}{|c|}{ Valores da Venda dos Direitos (USD em milhões) } \\
\hline Período & tv & Marketing & Hospitalidade & Licenciamento & Outros & Total \\
\hline $2007-2010^{6}$ & $\begin{array}{c}2448 \\
(63 \%)\end{array}$ & $\begin{array}{c}1097 \\
(28 \%)\end{array}$ & $\begin{array}{c}120 \\
(3 \%)\end{array}$ & $\begin{array}{c}71 \\
(2 \%)\end{array}$ & $\begin{array}{c}154 \\
(4 \%)\end{array}$ & $\begin{array}{c}3890 \\
(100 \%)\end{array}$ \\
\hline $2011-2014^{7}$ & $\begin{array}{c}2484 \\
(48 \%)\end{array}$ & $\begin{array}{c}1629 \\
(32 \%)\end{array}$ & $\begin{array}{c}185 \\
(4 \%)\end{array}$ & $\begin{array}{c}115 \\
(2 \%)\end{array}$ & $\begin{array}{c}724 \\
(14 \%)\end{array}$ & $\begin{array}{c}5137 \\
(100 \%)\end{array}$ \\
\hline $2015-2018^{8}$ & $\begin{array}{c}3127 \\
(49 \%)\end{array}$ & $\begin{array}{c}1660 \\
(26 \%)\end{array}$ & $\begin{array}{c}712 \\
(11 \%)\end{array}$ & $\begin{array}{c}600 \\
(9 \%)\end{array}$ & $\begin{array}{c}322 \\
(5 \%)\end{array}$ & $\begin{array}{c}6421 \\
(100 \%)\end{array}$ \\
\hline
\end{tabular}

Fonte: FIFA.

Até a Copa do Mundo de 2010, o direito de transmissão televisiva correspondia à transmissão audiovisual do evento apenas via televisão (radiodifusão terrestre, satélite ou cabo). Na Copa do Mundo de 2014, essa configuração sofreu alterações, pois permitiu que a distribuição da transmissão audiovisual direta e "ao vivo", também, acontecesse por meio da internet, tanto por aplicativos quanto por sites. Nessa outra possibilidade de distribuição da transmissão, computou-se na Copa de 2014 um consumo de conteúdo via online e mobile equivalente de 9,6\% ${ }^{9}$ da população da internet global.

Para 2018, a FIFA manteve as possibilidades de distribuição da transmissão audiovisual ofertadas em 2014, apenas classificando de uma maneira diferente da usual. Isso porque a entidade internacional da modalidade esportiva futebol, reestruturou suas atribuições, de forma que os contratos de licença dos direitos de media fossem definidos em tv, Mobile e Internet.

5 Disponível em:<https://www.fifa.com/associations/>. Acesso em: 09 ago. 2018.

6 Relatórios Financeiros da FIFA - Período - (2007 - 2010) - Disponível em: <https://www.fifa.com/mm/document/affederation/administration/01/39/20/45/web_fifa_fr2010_eng[1].pdf>. Acesso em: 09 ago. 2018.

7 Relatórios Financeiros da FIFA - Período - (2011 - 2014) - Disponível em: <https://resources.fifa.com/mm/ document/affederation/administration/02/56/80/39/fr2014weben_neutral.pdf>. Acesso em: 09 ago. 2018.

8 Relatórios Financeiros da FIFA Período - (2015 - 2018) - Disponível em: <https://resources.fifa.com/image/ upload/xzshsoe2ayttyquuxhq0.pdf>. Acesso em: 19 set. 2019.

9 Television Audience Report 2014 FIFA WORLD CUP Brazil. Disponível em: <https://resources.fifa.com/image/ upload/2014-fifa-world-cup-braziltm-television-audience-report-2745557.pdf?cloudid=n3z25ncdjj9qdwjaltet>. Acesso em: 09 ago. 2018. 


\section{DISERTACIONES}

\section{ESTUDIOS}

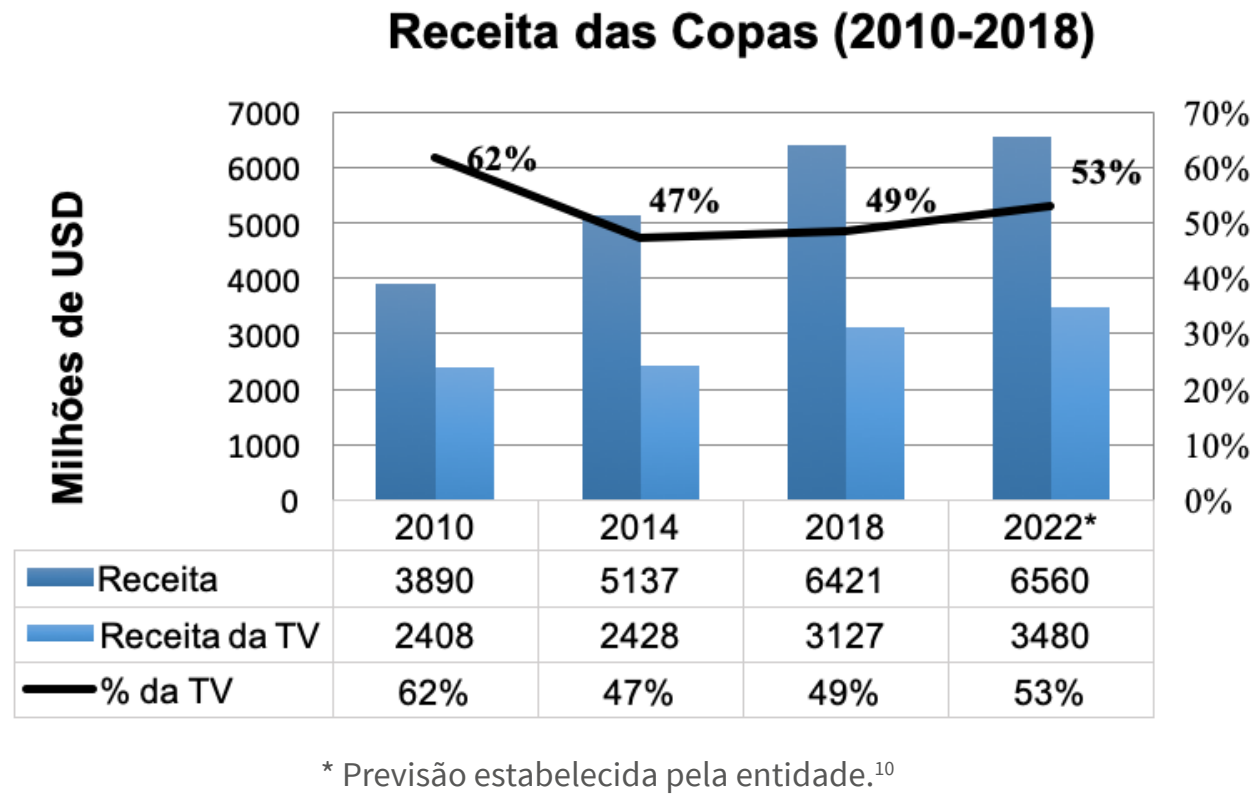

Gráfico 1. Dados das receitas da fIFA em períodos diferentes com o evento (Copa do Mundo)

Fonte: FIFA.

Esse interesse mundial pela competição justifica-se nas conexões que as pessoas criaram/criam com o esporte, neste caso o futebol, e as experiências que ele lhes proporciona, individualmente ou em grupo, por meio de um contato, muitas vezes, mediado pelos meios de comunicação de massa, uma vez que acompanhar o evento presencialmente é limitado, entre outras coisas, pela capacidade dos estádios e o distanciamento do espectador ao evento.

Portanto, segundo Coakley (2004), as coberturas mediáticas do esporte na sociedade abordam esse fenômeno social como uma forma de enfatizar os valores tradicionais da sociedade por meio de uma promoção social em manter as pessoas conectadas; o que Dayan e Katz (1994) qualificam como Media Event, ou seja, transmissões audiovisuais esportivas de um evento mundial, principalmente a final de um campeonato de futebol, tornam-se um evento midiático em que uma sociedade globalizada que se une temporalmente no mesmo instante, por meio do esporte, para manter um espírito de solidariedade mecânica, de maneira que há a idealização de uma versão de sociedade e uma ênfase tanto na unidade quanto na pluralidade de seres humanos. Assim, a cada edição, há uma tendência do evento atual de superar o recorde de audiência audiovisual da Copa anterior.

Além disso, há um fascínio pela transmissão audiovisual direta e "ao vivo" que persuade as pessoas a assistirem esses programas não só pelo conteúdo, mas devido a dois artifícios característicos desse tipo de comunicação: a imediaticidade e a vivacidade. Segundo Scannell (2014), a imediaticidade adquire um significado de real e de

10 Relatórios Financeiros da fIFA em que há a projeção para 2022 - Disponível em: < https://resources.fifa.com/ image/upload/fifa-financial-report-2017.pdf?cloudid=pinrmrodexmnqoettgqw>. Acesso em: 19 set. 2019. 


\section{DISERTACIONES}

ESTUDIOS

Estudios sobre imágenes en el nuevo ecosistema mediático

ISSN: $1856-9536$

Doi: https://doi.org/10.12804/revistas.urosario.edu.co/disertaciones/a.8298

Volumen 13, Número 2 / Julio-diciembre 2020

Versión PDF para imprimir desde

http://revistas.urosario.edu.co/index.php/disertaciones

verdadeiro, ou genuíno e autêntico entre os participantes nessa comunicação mediada, que só é estabelecido em interações presenciais e íntimas entre os componentes de um processo comunicacional. Já a vivacidade é a narrativa produzida do acontecimento esportivo pela transmissão, por meio das trocas de câmeras buscando o melhor ângulo e os replays, que é possível de ser realizada e mantida com os mecanismos de gravação audiovisual que "[...] capturam e preservam atos do discurso do evento ao vivo, a medida em que eles se desdobram no imediato momento da sua criação". ${ }^{11}$

Por isso, enquanto a imediaticidade é fugaz e não conserva os desdobramentos temporais das ações humanas na recordação, a vivacidade constrói um registro social, que é um resgate do momento enunciatório vivido. Logo, ao investigar a distribuição da transmissão audiovisual esportiva, faz-se necessário examinar, também, a persistência desse conteúdo depois do jogo, o chamado "melhores momentos", uma vez que são eles que reconstruíram o evento ao longo da programação de uma emissora, pontuando e direcionando a interpretação do espectador a qual a emissora adere. O pesquisador Umberto Eco (1984) chama esse conteúdo pós-jogo de falação esportiva, que tem como propósito alimentar a imprensa esportiva, para disciplinar e controlar os impulsos dos espectadores.

\section{Método}

Esta pesquisa realizou um estudo de caso orientado pelas normas de Yin (2001) que "[...] propicia explorar aquelas situações nas quais a intervenção que está sendo avaliada não apresenta um conjunto simples e claro de resultados" (p. 34). Selecionou-se como contexto o jogo em que a seleção do Brasil foi eliminada da Copa do Mundo de 2018, uma vez que, devido à importância do campeonato para o brasileiro, esse fato geraria repercussão pós-jogo ao longo da programação da emissora generalista e aberta.

A amostra foi composta pelas empresas de comunicação licenciadas no Brasil pela fifa para transmitir a partida. As licenças audiovisuais foram concedidas para тv, Mobile (aplicativos de celular ou tablet) e internet (site). Dessa forma, foram coletados os dados das transmissões audiovisuais, direta e "ao vivo", distribuídas pela emissora de TV aberta (Globo), emissoras de tv por assinatura (Sportv e fox Brasil); dos aplicativos para dispositivos móveis (Globoplay, Globo Esporte (GE), Sportv Copa 2018, fox Sports) e site (GloboEsporte.com e Globosat Play, Sportv). Apesar da Fox não ter licença da FIFA para distribuir o sinal da transmissão via mobile, segundo a tabela 2, houve uma distribuição.

Essa partida aconteceu dia 6 de julho, sexta-feira, às 15 horas, um dia de semana. No fluxo de programas de uma emissora de televisão aberta, essa transmissão produz uma desordem na grade de programação devido à presença de programas pré-fixados. Nas emissoras por assinatura específica em esportes, não houve distúrbios no fluxo da emissora, uma vez que a grade de programação é flexível e a transmissão direta e "ao vivo" é seu principal produto. E nos aplicativos e site não há fluxo de programas.

Após a partida, nas vinte e quatro horas seguintes, foi acompanhada a distribuição do conteúdo extraído do jogo nos principais programas da grade de programação da emissora generalista e aberta, a tv Globo, e nos aplicativos e sites anteriormente descritos.

11 Tradução livre de: “(...) audio (for radio) and audio-visual recordings (for television) capture and preserve live speech act events as they unfold in the immediate now of their coming into being." (Scannell, 2014, p. 96). 


\section{DISERTACIONES}

\section{ESTUDIOS}

Estudios sobre imágenes en el nuevo ecosistema mediático

ISSN: $1856-9536$

Doi: https://doi.org/10.12804/revistas.urosario.edu.co/disertaciones/a.8298

Volumen 13, Número 2 / Julio-diciembre 2020

Versión PDF para imprimir desde

http://revistas.urosario.edu.co/index.php/disertaciones

Foram observados e descritos em diferentes dispositivos os principais aspectos técnicos, positivos (+) e negativos (-), da distribuição ou recepção da transmissão e a propriedade técnica da imagem e som. Após o jogo, monitoraram-se as seguintes variáveis na emissora de tv: o nome do programa que inseriu trechos do jogo no seu conteúdo, o gênero e a sua duração. Nos aplicativos e sites, averiguaram-se quais as informações a respeito do jogo ficaram disponíveis para o usuário após o término da partida.

\section{Tabela 2. Licença sobre os direitos de media informada pela FIFA para o Brasil ${ }^{12}$}

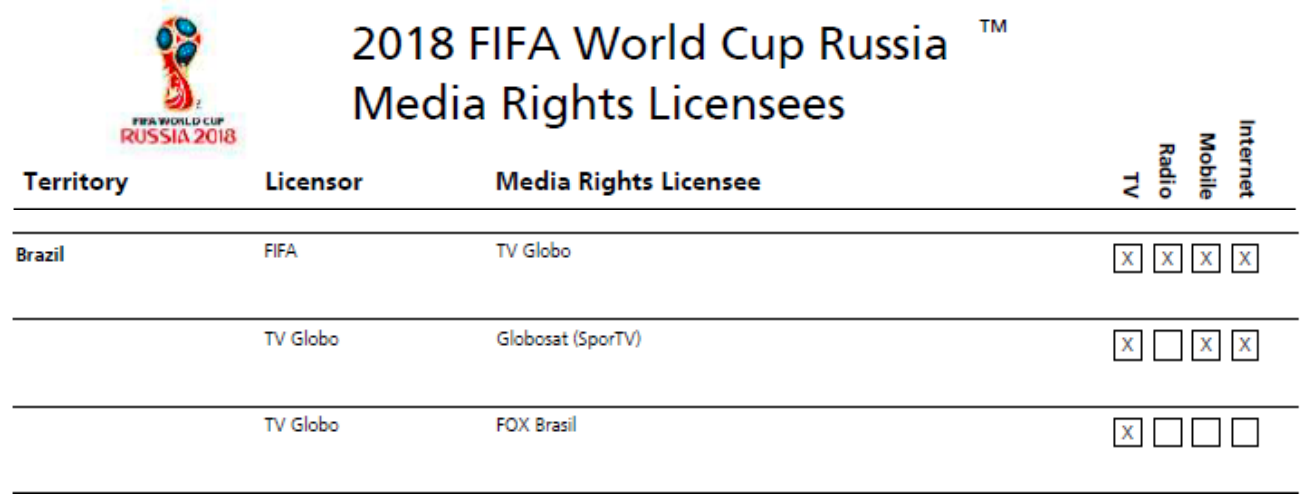

Fonte: FIFA (2018).

\section{Resultados}

A transmissão direta e "ao vivo" da partida de futebol foi distribuída por três emissoras de televisão brasileira, em quatro aplicativos e dois sites.

A tv Globo distribuiu a transmissão dos jogos no sinal de radiodifusão terrestre e aberto, tanto no sistema de televisão analógico (PAL-M) quanto digital (ISDB-T $\mathrm{T}_{\mathrm{B}}$ ), uma vez que o Brasil se encontra em processo de migração de um sistema para o outro. A distribuição da transmissão nesta emissora aconteceu, portanto, de três formas diferentes: uma analógica e duas digitais, uma vez que o sistema digital brasileiro, ISDB- ${ }_{\mathrm{B}}$, permite que, dentro de uma banda de canal uHF, existam treze segmentos para a transmissão de dados, de forma que doze partes desses segmentos ficam destinadas ao sinal de alta definição (HDTV) da emissora e uma parte fornece o sistema oneseg (1seg), que é a possibilidade do sinal de tv ser móvel ${ }^{13}$ e portátil. ${ }^{14}$

12 Disponível em: <https://resources.fifa.com/image/upload/media-rights-licensees-2018-fifa-world-cup-russiatm.pdf?cloudid=pen8htxngdj093i6oxbh>. Acesso em: 09 ago. 2018.

13 Segundo a ABNT (2007), recepção móvel via radiodifusão é o sinal de tv recebido com o aparelho em movimento, em qualquer hora e local, desde que não esteja em uma área de sombra.

14 Segundo a ABNT (2007), recepção portátil via radiodifusão é o sinal de tv recebido por diversos equipamentos, celular, pen-тv, televisão portátil, desde que seja equipado com um receptor adequado para captar o sinal. 


\section{DISERTACIONES}

Estudios sobre imágenes en el nuevo ecosistema mediático

ISSN: $1856-9536$

Doi: https://doi.org/10.12804/revistas.urosario.edu.co/disertaciones/a.8298

Volumen 13, Número 2 / Julio-diciembre 2020

Versión PDF para imprimir desde

http://revistas.urosario.edu.co/index.php/disertaciones

Tabela 3. Comparação entre as transmissões distribuídas pela TV Globo via radiodifusão

\begin{tabular}{|c|c|c|c|}
\hline $\begin{array}{l}\text { Sinais na Tv } \\
\text { aberta }\end{array}$ & Analógico & Digital & Oneseg \\
\hline Imagem & & & \\
\hline Aspecto $(+)$ & $\begin{array}{l}\text { Menor latência (atraso de } \\
\text { entrega do sinal ao receptor) }\end{array}$ & Melhor qualidade de imagem & Portabilidade e mobilidade \\
\hline Aspecto (-) & $\begin{array}{l}\text { Pior qualidade } \\
\text { de imagem }\end{array}$ & Interrupções de audiovídeo & Instabilidade no sinal \\
\hline Propriedade & $\begin{array}{l}\text { pal-m } \\
525 \text { linhas } \\
(4: 3) \\
\text { Até } 2 \text { canais de som }\end{array}$ & $\begin{array}{l}\text { hdtv } \\
1.280 \times 720 \text { pixels }(16: 9) \\
\text { Até } 5 \text { canais de som }\end{array}$ & $\begin{array}{l}\text { qvga } \\
320 \times 240 \text { pixels } \\
(4: 3) \\
\text { Até } 2 \text { canais de som }\end{array}$ \\
\hline
\end{tabular}

Fonte: elaboração própria (2019).

A Sportv, emissora de televisão por assinatura pertencente ao Grupo Globo, distribuiu o jogo via cabo/satélite em um dos seus três canais (tabela 4), no formato Full-но. A emissora também disponibilizou a opção de assistir ao jogo via IPTV, Internet Protocol Television, na qualidade $4 \mathrm{~K}^{15}$ que foi distribuído em dois formatos: um com narrativa visual construída por recorte das várias câmeras e locução e narração nacional; e o outro sem recortes, com áudio ambiente e sem locução e comentários.

15 4K - UDH ou ultra-HD - definição de imagem em 3840 × 2160 pixels ou seja, 8 milhões de pixels na tela de proporção 16:9. 


\section{DISERTACIONES}

ESTUDIOS

Estudios sobre imágenes en el nuevo ecosistema mediático

ISSN: $1856-9536$

Doi: https://doi.org/10.12804/revistas.urosario.edu.co/disertaciones/a.8298

Volumen 13, Número 2 / Julio-diciembre 2020

Versión PDF para imprimir desde

http://revistas.urosario.edu.co/index.php/disertaciones

Tabela 4. Comparação entre as transmissões distribuídas pela SporTV

\begin{tabular}{|c|c|c|}
\hline $\begin{array}{l}\text { Sinais da TV por } \\
\text { assinatura } \\
\text { (cabo/satélite) }\end{array}$ & Sportv нD & Sportv 4K \\
\hline Imagem & & \\
\hline Aspecto (+) & Estabilidade no sinal & Melhor qualidade \\
\hline Aspecto (-) & Custo elevado & Custo elevado, latência (atraso) e picotamento da imagem \\
\hline Propriedade & $\begin{array}{l}\text { Full - HDTV } \\
1920 \times 1080 \text { pixels (16:9) } \\
\text { Até } 5 \text { canais de som }\end{array}$ & $\begin{array}{l}4 \mathrm{~K} \\
3840 \times 2160 \text { pixels } \\
(16: 9) \\
\text { Até } 7 \text { canais de som }\end{array}$ \\
\hline
\end{tabular}

Fonte: elaboração própria (2019).

A fox distribuiu o jogo nos seus dois canais (tabela 5), via cabo/satélite, de modo que a diferença entre eles ocorreu na locução e nos comentários das partidas. Na fox 1, o jogo foi narrado e comentado por homens. Na fox 2 , a narração foi feita por uma mulher, com comentários de um homem e uma mulher.

Tabela 5. Comparação entre as transmissões distribuídas pela fox

\begin{tabular}{|l|l|l|}
\hline \multicolumn{1}{|c|}{$\begin{array}{c}\text { Sinais da tv por assinatura } \\
\text { (cabo/satélite) }\end{array}$} & \multicolumn{1}{|c|}{ Fox 1} & Fox 2 \\
\hline Imagem & & \\
\hline Aspecto (+) & Boa qualidade \\
\hline Aspecto (-) & $\begin{array}{l}\text { Latência comparado a radiodifusão terrestre } \\
\text { Custo elevado }\end{array}$ \\
\hline Propriedade & $\begin{array}{l}\text { Full - HDTV } \\
1920 \text { x } 1080 \text { pixels (16:9) } \\
\text { Até } 5 \text { canais de som }\end{array}$ \\
\hline
\end{tabular}

Fonte: elaboração própria (2019). 
A distribuição da transmissão nos sites foi uma realocação do sinal televisivo no ambiente da web via browser independente do equipamento receptor (PC, smartphone ou tablet). No site do Globo Esporte, além do sinal televisivo, houve uma adição de elementos textuais, fotos, imagens, vídeos e o acesso às redes sociais, como uma ferramenta que proporcionasse ao usuário uma experiência de interatividade com o conteúdo e com a ubiquidade.

Tabela 6. Comparação entre as transmissões distribuídas na web

\begin{tabular}{|l|c|c|}
\hline \multicolumn{1}{|c|}{ Site } & Globo Esporte.com & Sportv \\
\hline Imagem & $\begin{array}{c}\text { Arrasado por trio belga no 10 tempo, } \\
\text { Brasil perde e está fora da copa do } \\
\text { Mundo }\end{array}$ & \\
\hline Aspecto (+) & Informações extras & Transmissão audiovisual na web via browser - portabilidade \\
\hline Aspecto (-) & Necessidade de assinatura de pacote de tv e internet \\
\hline Propriedade & Depende do equipamento e da conexão com a internet \\
\hline
\end{tabular}

Fonte: elaboração própria (2019).

Os aplicativos redistribuíram as transmissões elaboradas pelas emissoras Globo, Sportv e fox em um receptor móvel/portátil, por meio da internet, de forma que as locuções e os comentários eram os mesmos que estavam presentes no sistema televisivo. Observa-se, em dois dos aplicativos, o da GE e o da fox, a criação de uma configuração estrutural no software que permitiu ao usuário receber informações escritas, extras, a respeito do jogo quando a tela de visualização não estava em modo de visualização "tela cheia". No entanto, notou-se que, no aplicativo do GE, as informações disponibilizadas eram as mesmas distribuídas no site do Globo Esporte.com. Diferente da fox, que buscou criar uma configuração específica para o aplicativo a partir da temática do conteúdo e da especificidade do meio. 
Tabela 7. Comparação entre as transmissões distribuídas pelos aplicativos

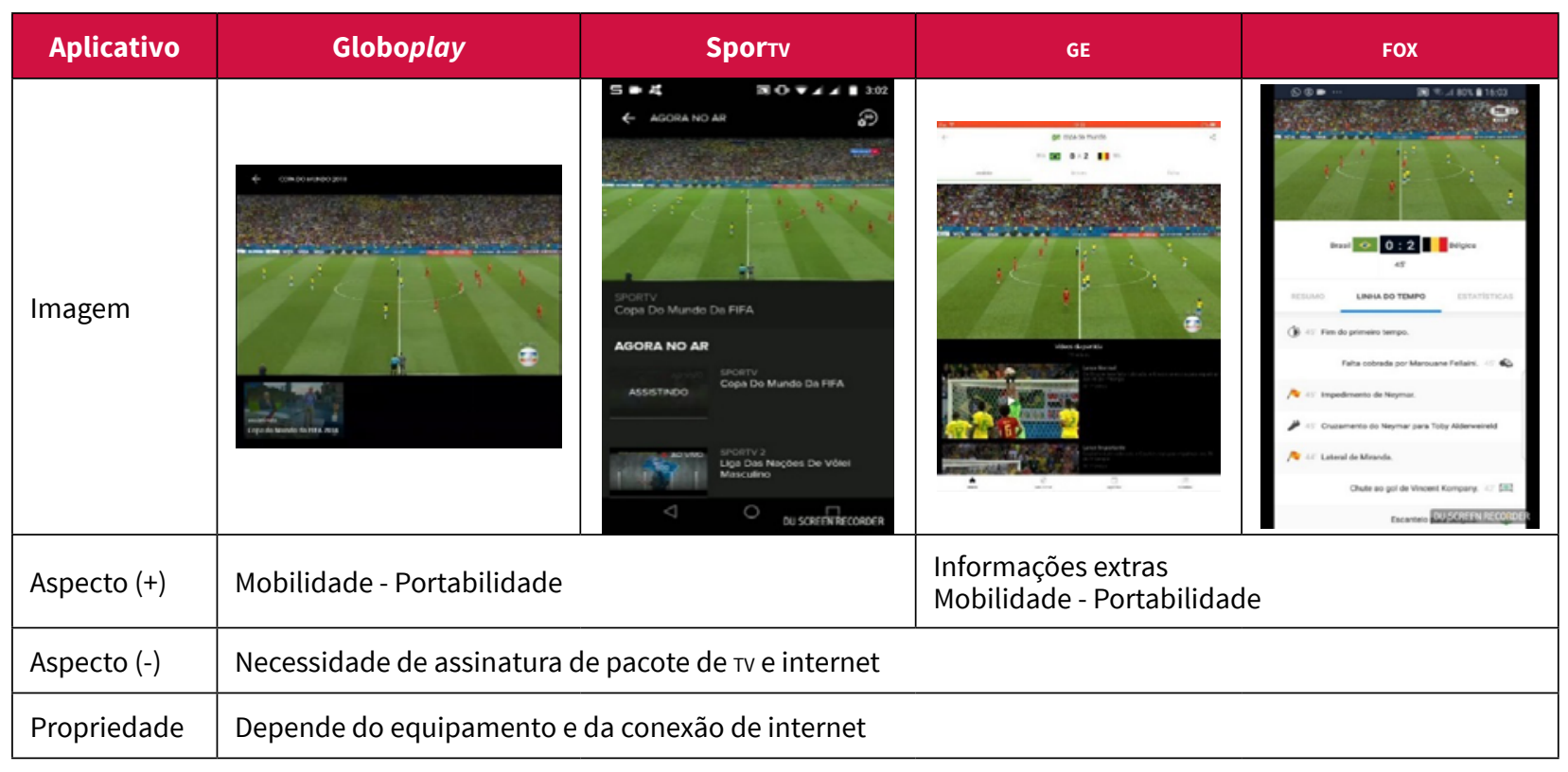

Fonte: elaboração própria (2019).

Nas vinte e quatro horas posteriores à transmissão, observou-se que os programas jornalísticos na grade de programação da emissora generalista e aberta, tv Globo, foram os que se utilizaram do conteúdo gravado na transmissão de diferentes formas. Nos Jornais Locais, ${ }^{16}$ segunda e primeira edição do dia seguinte, enfocou-se a reação da torcida antes da partida, nos momentos críticos, nos gols e depois do jogo; por isso, os mesmos utilizaram-se de uma quantidade pequena de imagens do jogo. Nos Jornais, Nacional e Hoje, as imagens do jogo foram mostradas para ilustrar a crônica jornalística esportiva. Sobre o assunto, houve também uma resenha feita pelo locutor Galvão Bueno, mas essa não foi ilustrada com imagens do jogo.

Outros dois programas da emissora apresentaram o uso das imagens da transmissão de formas diferentes das descritas acima. Com o objetivo de discutir os jogos e suas eventualidades, o programa Central da Copa dispôs das imagens do jogo para apontar questões envolvendo a atuação dos jogadores, os erros e acertos, e explicar embaraços táticos que aconteceram no jogo, embora houvesse a presença de duas crônicas ilustradas, uma para abrir e outra para fechar o programa.

O Jornal da Globo optou por explicar um elemento tático do jogo destacado pelos comentaristas da emissora durante a transmissão para justificar a derrota, além de apresentar os melhores momentos do jogo ao construir uma narrativa para destacar o melhor jogador da partida.

16 Jornal Local do Interior Paulista - TV TEM - região de Bauru. 


\section{ESTUDIOS}

\section{DISERTACIONES}

Estudios sobre imágenes en el nuevo ecosistema mediático

ISSN: $1856-9536$

Doi: https://doi.org/10.12804/revistas.urosario.edu.co/disertaciones/a.8298

Volumen 13, Número 2 / Julio-diciembre 2020

Versión PDF para imprimir desde

http://revistas.urosario.edu.co/index.php/disertaciones

Tabela 8.0 conteúdo da transmissão na grade de programação da tv Globo

\begin{tabular}{|c|c|c|c|c|}
\hline Programa & Gênero & $\begin{array}{c}\text { Duração da(s) } \\
\text { matéria(s) }\end{array}$ & $\begin{array}{c}\text { Duração das imagens } \\
\text { do jogo na(s) } \\
\text { matéria(s) }\end{array}$ & $\begin{array}{c}\text { Percentual das } \\
\text { imagens do jogo na(s) } \\
\text { matéria(s) }\end{array}$ \\
\hline Jornal local $-2^{\circ}$ ed. & $\begin{array}{l}\text { Jornalismo } \\
7 \text { matérias } \\
1 \text { da Copa }(14 \%)\end{array}$ & $3 \min 4 s$ & $11 \mathrm{~s}$ & $0.06 \%$ \\
\hline Jornal Nacional & $\begin{array}{l}\text { Jornalismo } \\
22 \text { matérias } \\
9 \text { da Copa }(40 \%)\end{array}$ & $15 \mathrm{~min} 23 \mathrm{~s}$ & $10 \mathrm{~min} 52 \mathrm{~s}$ & $66 \%$ \\
\hline Central da Copa & Debate & $35 \min 12 \mathrm{~s}$ & $8 \min 12 \mathrm{~s}$ & $23 \%$ \\
\hline Jornal da Globo & $\begin{array}{l}\text { Jornalismo } \\
9 \text { matérias } \\
2 \text { da Copa }(22 \%)\end{array}$ & $6 \mathrm{~min} 09 \mathrm{~s}$ & $2 \min 34$ & $41 \%$ \\
\hline Jornal local - $1^{\circ}$ ed. & $\begin{array}{l}\text { Jornalismo } \\
8 \text { matérias } \\
1 \text { da Copa }(12 \%)\end{array}$ & $4 \mathrm{~min} 40 \mathrm{~s}$ & $1 \mathrm{~min} 05 \mathrm{~s}$ & $26 \%$ \\
\hline Jornal Hoje & $\begin{array}{l}\text { Jornalismo } \\
16 \text { matérias } \\
4 \text { da Copa ( } 25 \%)\end{array}$ & $5 \mathrm{~min}$ & $1 \mathrm{~min} 54 \mathrm{~s}$ & $39 \%$ \\
\hline
\end{tabular}

Fonte: Globo (2018).

Os aplicativos conservaram, após o jogo e o término do evento, diferentes conteúdos, de maneira que era possível assistir novamente o jogo na íntegra (Globoplay), ver apenas os melhores momentos, ler os comentários a respeito do jogo ou ler apenas um resumo dos acontecimentos do jogo, em uma disposição cronológica e estatística. 


\section{DISERTACIONES}

ESTUDIOS

Estudios sobre imágenes en el nuevo ecosistema mediático ISSN: $1856-9536$

Doi: https://doi.org/10.12804/revistas.urosario.edu.co/disertaciones/a.8298 Volumen 13, Número 2 / Julio-diciembre 2020

Versión PDF para imprimir desde

Tabela 9. 0 conteúdo da transmissão nos aplicativos após o término do evento

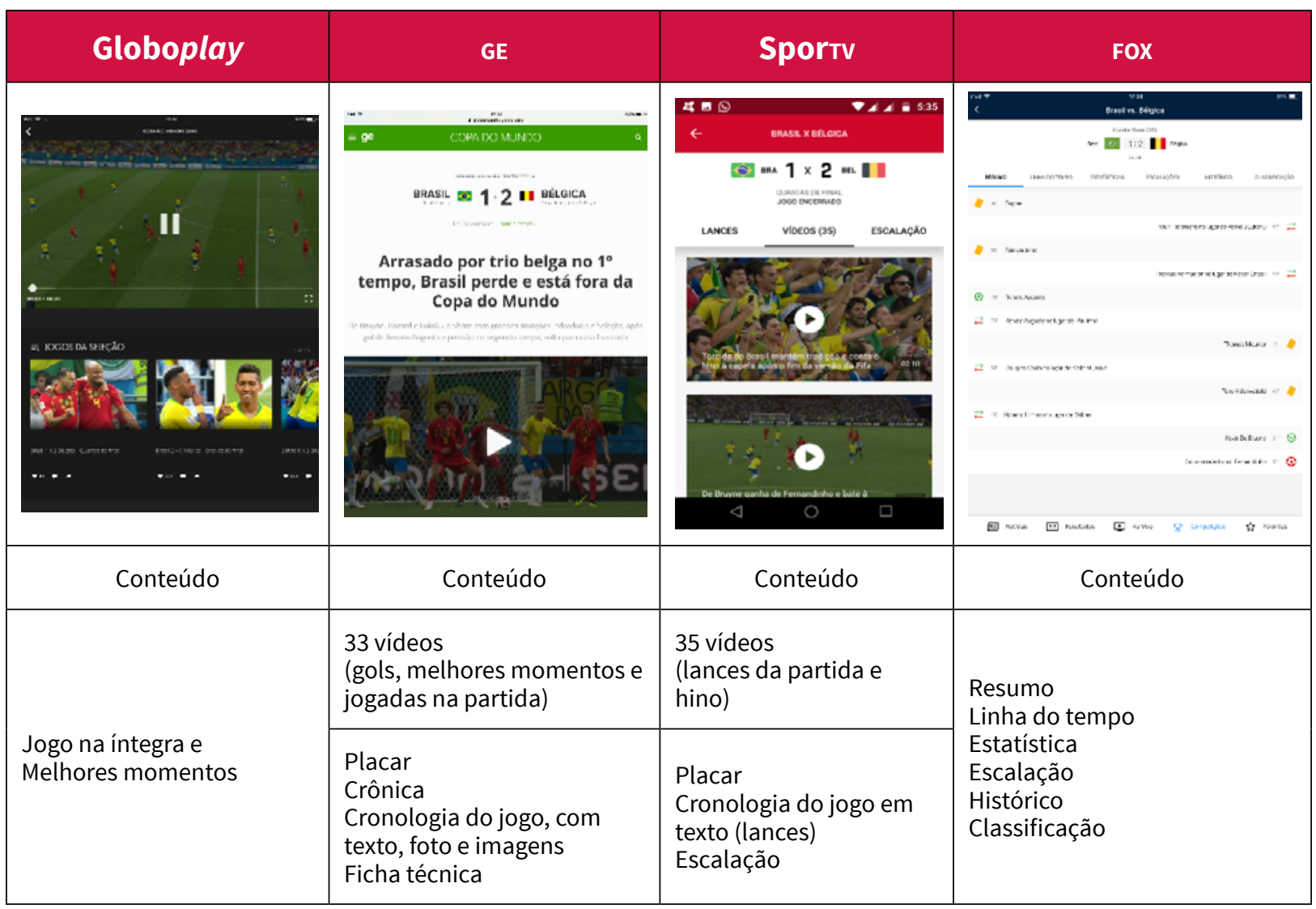

Fonte: elaboração própria (2019).

Nos sites, a Sportv não criou uma proposta de disponibilizar conteúdo pós-jogo, apenas de exibir a transmissão direta e "ao vivo" por meio da internet. Já o Globo Esporte.com, manteve a página na web com as informações que foram produzidas durante a partida e logo após o término da partida, para que o usuário pudesse recordar, rever algum momento do jogo, curtir ou compartilhar nas redes sociais. Essa estrutura já é oferecida pelo site, ao fazer a cobertura de outros campeonatos de futebol pelo mundo. 


\section{DISERTACIONES}

ESTUDIOS

Estudios sobre imágenes en el nuevo ecosistema mediático

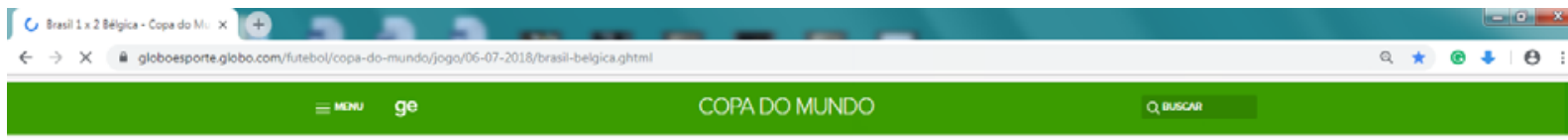

BRASIL

Arrasado por trio belga no $1^{\circ}$ tempo, Brasil perde e está fora da Copa do Mundo

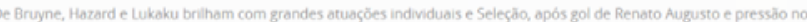

segundo tempo, volta para casa frustrad.

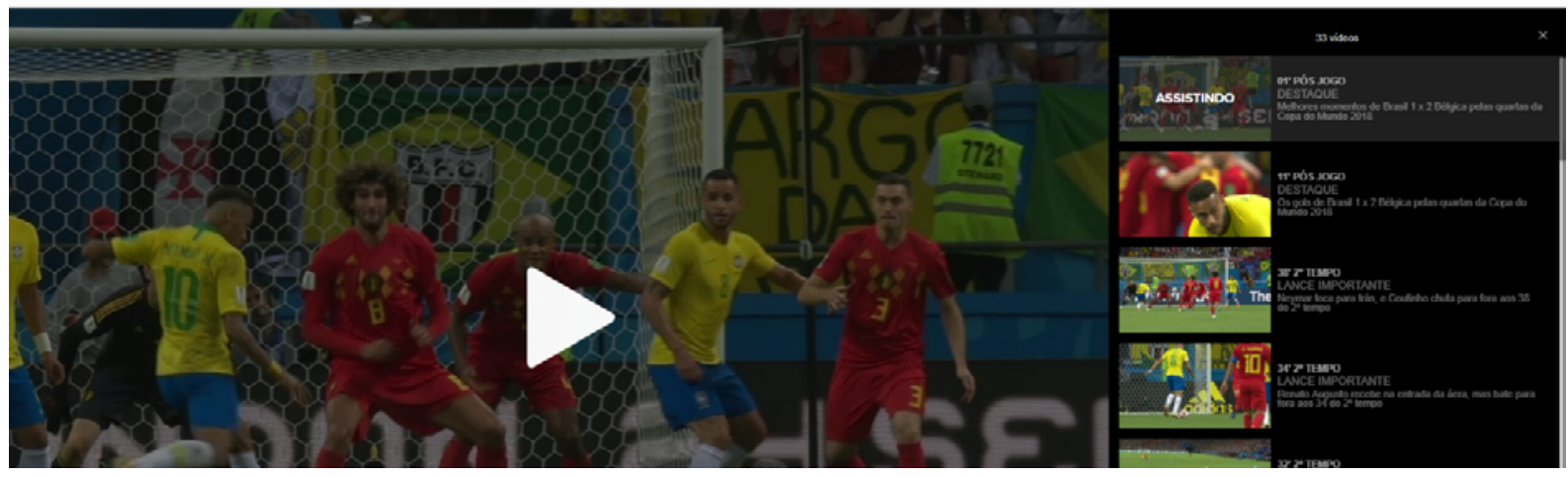

Imagem 1. Página do Jogo Brasil x Bélgica no site do Globo Esporte.com

Fonte: Globo (2018).

\section{Discussões}

A fIFA tornou-se uma entidade corporativa, produtora de eventos esportivos com ambições planetárias, que utiliza a globalização da media como seu paradigma para enfrentar os desafios tecnológicos do ambiente digital, direitos autorais de imagem e acesso ao conteúdo produzido pelo evento. Com isso, a partir da Copa de 2010, a entidade assumiu as múltiplas dimensões da comunicação mediática que, segundo Waisbord (2014), “[...] mudaram as condições e rotinas do trabalho da media, fazendo da interconectividade o ponto central na forma como o conteúdo é produzido, distribuído e comercializado" (p. 29), ${ }^{17} \mathrm{em}$ torno da transmissão televisiva. Dessa forma, a entidade propõe entregar por contrato às empresas de comunicações nacionais, uma transmissão audiovisual finalizada, ou seja, um produto para apenas ser distribuído pelas emissoras nacionais ao seu público em três diferentes possibilidades (Tv, Mobile, Internet).

17 Tradução livre de: Global networks have also changed the conditions and routines of media work, making interconnectivity central to the way content is produced, distributed, and marketed (Waisbord, 2014, p. 29). 


\section{DISERTACIONES}

Essa transmissão produzida pela FIFA tem o objetivo de ser um programa e um formato que atravessem os limites da nacionalidade. Keane, Fung e Moran (2007) descrevem esse posicionamento como a tese de um capitalismo digital de estrutura global dominante, em que o interesse da entidade controla a media, que, por sua vez, atua como veículo de controle ideológico, proporcionando uma homogeneização cultural que "[...] reduz a diversidade através das sociedades, enquanto a diversidade dentro da sociedade sofre por causa da excessiva concentração mediática”. ${ }^{18}$ Por isso, a FIFA, ao estabelecer "[...] os acordos de distribuição, juntamente com economias de escala e escopo, aumentam ainda mais a dificuldade enfrentada pelas pequenas organizações de mídia que competem na mesma área linguística". ${ }^{19}$

Essa forma de mediação adotada pela entidade tenta excluir a interferência dos estados e das nações em relação ao seu conteúdo central, a transmissão, o que promoveria, na teoria, a experiência mediática de um espectador unificado mundialmente. Contudo, Waisbord (2014) aponta que esse paradigma de globalização de media praticado pela fIFA contem limitações, uma vez que não está desconectado das ações e dos atores comunicacionais nacionais e locais. A manifestação dos limites nacionais materializa-se nas legislações dos países sob a administração dos Estados em que esse produto cultural é distribuído, principalmente em dois aspectos, nas questões políticas e técnicas envolvendo os meios.

Segundo Williams (2016), esses dois aspectos governam o sistema comunicacional televisivo desde o surgimento da radiodifusão no mundo, pois há uma relação intrínseca entre político e técnico. 0 equilíbrio ou a sobreposição de um aspecto sobre o outro depende do poder que as instituições envolvidas possuem em cada sociedade, como observado por Williams (2016) na Grã-Bretanha e nos EUA. No Brasil, Bolaño (2014) salienta que o sucesso da indústria de tv privada se deu em função do favorecimento que o regime militar ofereceu a poucas empresas de comunicação, com o intuito desse governo em consolidar o mercado interno sob o controle estatal de transmissão, pesquisa e desenvolvimento do meio.

O desdobramento desse cenário resultou, no aspecto técnico, em um sistema de televisão analógico que beneficiou as empresas de bens de consumo, que foi substituído no início do século XXI por um novo padrão de televisão, o sistema digital ISDB- ${ }_{\mathrm{B}}{ }^{20}{ }^{20}$ Ao definir esse padrão de TV, o Estado brasileiro ampliou as possibilidades da radiodifusão, propiciando novos recursos de forma gratuita para a população, tais como: alta definição de imagem e som, interatividade na TV, multiprogramação, portabilidade e mobilidade do sinal televisivo. Dentre os novos recursos ofertados pela tecnologia digital de radiodifusão, a portabilidade e a mobilidade do sinal interferiam diretamente nos planos de negócios pretendidos pela telecomunicação brasileira, de capital privado e estrangeiro. No aspecto político, houve uma redução sistemática da competitividade entre as empresas de radiodifusão, o que acabou propiciando uma concentração e uma centralização de poder em torno de uma empresa, a Globo (Bolaño \& Brittos, 2005; Lima, 2006).

18 Tradução livre de: Cultural homogenization reduces diversity across societies, while diversity within society suffers because of excessive media concentration (Keane et al., 2007, p. 41).

19 Tradução livre de: Distribution agreements, along with economies of scale and scope, further compound the difficulty faced by small media organizations competing in the same language pond (KEANE et al., 2007, p. 51).

20 Decreto n5.820, de junho de 2006. Dispõe sobre a implantação do SBTVD-T, estabelece diretrizes para a transição do sistema de transmissão analógica para o sistema de transmissão digital do serviço de radiodifusão de sons e imagens e do serviço de retransmissão de televisão, e dá outras providências. Disponível em: <http:// www.planalto.gov.br/ccivil_03/_Ato2004-2006/2006/Decreto/D5820.htm>. Acesso em: 09 ago. 2018. 


\section{DISERTACIONES}

ESTUDIOS

Estudios sobre imágenes en el nuevo ecosistema mediático

ISSN: $1856-9536$

Doi: https://doi.org/10.12804/revistas.urosario.edu.co/disertaciones/a.8298

Volumen 13, Número 2 / Julio-diciembre 2020

Versión PDF para imprimir desde

http://revistas.urosario.edu.co/index.php/disertaciones

A Globo tornou-se a principal empresa brasileira de radiodifusão, imperando por efeito acumulativo, pois combinou o domínio do direito de media da transmissão com a sua tecnologia e o seu status nacional, o que a propiciou explorar, de diferentes maneiras, a distribuição da transmissão, sustentada na ânsia da população brasileira pelo conteúdo esportivo, principalmente devido à importância cultural adquirida pelo evento e uma crença na capacidade da radiodifusão em transmitir, instantaneamente, um conteúdo audiovisual legítimo.

Consequentemente, essa supremacia da Globo permitiu à empresa usufruir de uma perspectiva financeira que justificasse obter uma licença especial junto à FIFA, o que possibilitou a ela renegociar, diretamente, a distribuição dos direitos de media da Copa com outras empresas privadas de comunicação no Brasil (tabela 2), Sportv e fox. Essa ação da Globo restringiu, no setor de tevê por assinatura, a sua principal concorrente, a fox, pelo menos em contrato (tabela 2), a distribuir o evento nos seus dois canais de tevê por assinatura. Entretanto, na prática, a fox distribuiu, também, a transmissão direta e "ao vivo" dos jogos, por meio do seu aplicativo em dispositivos móveis e portáteis (tabela 7).

A distribuição da transmissão direta e "ao vivo" da Copa ocorreu de forma gratuita por meio de todos os sistemas de radiodifusão terrestre (TV). Esse recurso foi dominado e conduzido conforme o interesse da Globo, única emissora de canal aberto a transmitir o evento. A emissora também ofereceu, por meio da internet, outra possibilidade de assistir ao jogo para quem dispunha de equipamento móvel e portátil, mas não tinha neles a antena para captar o sinal oneseg. A internet propiciou a conexão do usuário com o aplicativo da emissora ou com a sua página na rede. Nesta forma de distribuição do jogo, houve uma integração de dois setores da comunicação, a radiodifusão terrestre e a telecomunicação. Segundo Keane et al. (2007), a televisão começa a ser influenciada pela tecnologia da informação, de modo que o conteúdo televisivo se torna uma fonte de ligação entre o receptor e a marca; o conteúdo passa a ser distribuído por outros dispositivos, o que permite estabelecer um vínculo particularizado entre os polos. Seguindo nesse sentido, a emissora busca experienciar as competências disponibilizadas pela internet, oferecendo, gratuitamente, uma maior quantidade de informação para o acesso do usuário, no aplicativo e no site (tabela 6 e 7 - item GE), na tentativa de criar um formato original para esse conteúdo nesse meio e um hábito de consumo.

A distribuição do jogo para o telespectador, com recursos econômicos para assinar um plano de TV, possuir um equipamento televisivo que suportasse a tecnologia de alta definição de imagem (Full-HD e 4K) e uma banda larga acima de 50 mega de velocidade de dados de download, pode estabelecer diversas combinações entre esses elementos na sua recepção para acompanhar o evento, tv por assinatura (HD, Full-HD; Fox e Sportv) e IPTV (HD, Full-HD e 4K; Fox e Sportv). Nos canais de televisão por assinatura via cabo/satélite (Sportv e fox), a peculiaridade entre as transmissões encontrava-se na questão da locução e dos comentários do jogo. Nos aplicativos, criou-se a possibilidade de se acompanhar o jogo interagindo com outras tarefas ou as informações em locais variados. E, via IPTV, houve a possibilidade de se escolher entre dois formatos de transmissão.

Após o jogo e a sua transmissão, a emissora aberta inseriu as imagens do mesmo na sua grade de programação por meio dos telejornais e do seu programa de debates, não havendo uma reprise do jogo na íntegra ou uma versão compacta dos melhores momentos. No telejornalismo, as imagens foram utilizadas para ilustrar, principalmente, as crônicas jornalísticas esportivas, direcionando a percepção do telespectador para uma interpretação ou leitura dos acontecimentos esportivos. No programa de debates propostos pela emissora, apenas as imagens polêmicas foram exibidas, em diferentes ângulos e velocidades, visando o comentário e a discussão entre os participantes. Dessa 


\section{DISERTACIONES}

ESTUDIOS

Estudios sobre imágenes en el nuevo ecosistema mediático

ISSN: $1856-9536$

Doi: https://doi.org/10.12804/revistas.urosario.edu.co/disertaciones/a.8298

Volumen 13, Número 2 / Julio-diciembre 2020

Versión PDF para imprimir desde

http://revistas.urosario.edu.co/index.php/disertaciones

forma, o telespectador, por meio da televisão, obteve acesso apenas a trechos do jogo selecionado pela emissora, em momentos da programação. A possibilidade de interagir com a transmissão completa do jogo aconteceu apenas por meio do aplicativo do Globoplay. Nos demais ambientes possibilitados pela internet (tabela 09 e imagem 1), 0 acesso também ficou restrito a trechos do jogo ou aos dados cronológicos e estatísticos da partida.

Esse registro social da partida foi, portanto, organizado em recortes, na maioria dos casos, além de terem sido direcionados por comentários construídos pelas emissoras detentoras dos direitos de media, que os distribuíram pela programação, nos telejornais e programas de debates esportivos. A transmissão completa do jogo estava disponível apenas via streaming, na plataforma da principal emissora de radiodifusão brasileira, Globoplay, que requer assinatura. Por isso, verifica-se que, nesse caso, a "[...] governança global não tem impacto imediato no trabalho cotidiano da mídia", ${ }^{21}$ ou seja, a padronização da FIFA como única representação mundial do jogo acaba modificando-se ao receber elementos locais possibilitados pela forma de distribuição da transmissão audiovisual na tv e internet. E após o jogo, com a edição da transmissão pelas emissoras detentoras dos diretos de transmissão.

\section{Considerações}

Atualmente, a Copa do Mundo conecta-se ao espectador por meio da transmissão audiovisual produzida pela FIFA, que propõe construir uma experiência unificada do evento, para ser distribuída pelas emissoras mundiais. Por isso, compete às emissoras nacionais licenciadas planejar e organizar a distribuição desse programa de forma a preservar as principais características do produto, a imediaticidade e vivacidade, mas direcionada as peculiaridades locais como os aspectos tecnológicos, políticos e culturais.

No caso observado, a configuração política do meio televisivo é conduzida pelo sistema privado e de sinal aberto (Globo) que assegura uma distribuição gratuita das transmissões esportivas do jogo e dita a direção que as outras emissoras deveriam seguir (Sportv e fox Brasil). Interligado a essa política local está um sistema tecnológico televisivo e de telecomunicação singular que possibilita inúmeros recursos técnicos integrados (mobilidade, portabilidade, alta definição, interatividade...) que conduz a prática de visualização na tv por meio das possibilidades de distribuição, inserções da transmissão na grade de programação e locução. No ambiente da internet, aplicativos e site, devido à usabilidade e configurações que recebe a transmissão, com ou sem informações extras.

Por isso, as questões técnicas do meio acabam direcionando a distribuição do produto cultural, uma vez que a distribuição da transmissão audiovisual esportiva obedeceu a materialidade do meio e foi oferecida dentro do fluxo da grade de programação da emissora no momento em que o evento acontece. Essa experiência por meio da televisãotv ocorreu em uma dimensão de tempo em que o telespectador estava consciente de que o programa a que estava assistindo terminaria e algo novo tomaria o lugar da transmissão. Por consequência, para manter um compartilhamento dessa história contada pela transmissão, a emissora preparou inserções desse material de maneira direcionada ao longo da sua programação, retomando em diversas perspectivas apresentadas pela transmissão.

21 Tradução livre de: Global governance does not have an immediate impact on everyday media work (Waisbord, 2014, p. 37). 


\section{DISERTACIONES}

\section{ESTUDIOS}

Estudios sobre imágenes en el nuevo ecosistema mediático

ISSN: $1856-9536$

Doi: https://doi.org/10.12804/revistas.urosario.edu.co/disertaciones/a.8298

Volumen 13, Número 2 / Julio-diciembre 2020

Versión PDF para imprimir desde

http://revistas.urosario.edu.co/index.php/disertaciones

Já quem acompanhou o jogo por meio da internet, via site ou aplicativo, obteve a possibilidade de continuar na história contada pelo jogo após seu término, uma vez que os sites ou aplicativos disponibilizam conteúdos como vídeos de lances do jogo, vídeos com os melhores momentos, estatísticas da partida e texto com comentários e análise do jogo, que alimentavam o interesse do usuário pelo tema, inclusive com alguma possibilidade de este se manifestar via rede social. Com isso, o torcedor não é mais projetado para fora do tema como ocorre na TV aberta.

\section{Referência}

1. Associação Brasileira De Normas Técnicas (2007). ABNTNBR 15604:2007. Televisão digital terrestre-Receptores.

2. Bolaño, C. (2014). Globalization and history in Brazil: Communication, culture, and development policies at a crossroads. In M. Guerrero \& M. Ramirez (Eds.), Media systems and communication policies in Latin America (pp. 226-242). Mexico City: Universidad Iberoamericana.

3. Bolaño, C., \& Brittos, V. (2005). Rede Globo - 40 anos de poder e hegemonia. São Paulo: Paulus.

4. Coakley, J. (2004). Sport in society: Issues and controversies $8^{\circ}$ ed. New York: Mc Graw Hill.

5. Dayan, D., \& Katz, E. (1994). Media events: The live broadcasting of history. Cambridge: Harvard University Press.

6. Eco, U. (1984). Viagem na irrealidade cotidiana. Rio de Janeiro: Nova Fronteira.

7. Fechine, Y. (2008). Televisão e presença: uma abordagem semiótica da transmissão direta. São Paulo: Estação das Letras e Cores.

8. Keane, M., Fung, A., \& Moran, A. (2007). New television, globalization, and East Asian cultural imagination. Hong Kong: Hong Kong University Press.

9. Lima, V. A. (2006). Mídia - Crise política e poder no Brasil. São Paulo: Perseu Abramo.

10. Scannell, P. (2014). Television and the meaning of live. Cambridge: Polity Press.

11. Vigarello, G., \& Holt, R. (2009). O corpo trabalhado. In A. Corbin, J. Courtine \& G. Vigarello (Eds.), História do corpo: da revolução à grande guerra $3^{\circ}$ ed. (pp. 393-478). Petropolis: Vozes.

12. Waisbord, S. (2014). Latin America media and the limitations of the media 'globalization' paradigm. In M. Guerrero \& M. Ramirez (Eds.) Media systems and communication policies in Latin America (pp. 24-42). Mexico City: Universidad Iberoamericana.

13. Williams, R. (2016). Televisão: tecnologia e forma cultural. São Paulo: Boitempo.

14. Yin, R. (2001). Estudo de caso: planejamento e métodos $2^{\circ}$ ed. Porto Alegre: Bookman. 